\title{
Correction to: Changes of Affective States in Intelligent Tutoring System to Improve Feedbacks Through Low-Cost and Open Electroencephalogram and Facial Expression
}

\author{
Wellton Costa de Oliveira, Ernani Gottardo, \\ and Andrey Ricardo Pimentel
}

\section{Correction to: \\ Chapter "Changes of Affective States in Intelligent Tutoring System to Improve Feedbacks Through Low-Cost and Open Electroencephalogram and Facial Expression" in: \\ V. Kumar and C. Troussas (Eds.): Intelligent Tutoring Systems, LNCS 12149, https://doi.org/10.1007/978-3-030-49663-0_8}

The original version of the chapter was inadvertently published without incorporating the author's proof corrections. The chapter has now been corrected and approved by the author. 